Historia

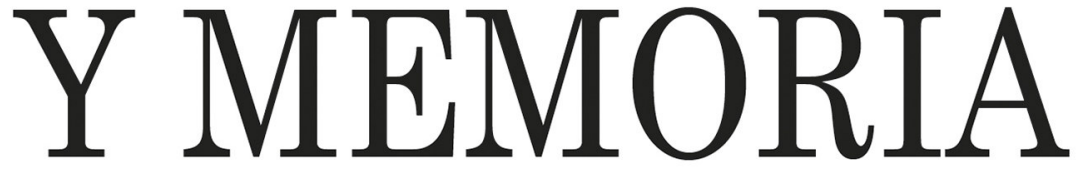

ISSN: 2027-5137 Julio - Diciembre, Año 2016 - Tunja, Colombia

La enseñanza de la lectura como profilaxis:

el Decreto Orgánico de Instrucción

Pública: entre la caridad y la instrucción

Diana Paola Guzmán Méndez

Páginas: 121 - 149

DOI: http://dx.doi.org/10.19053/20275137.5202

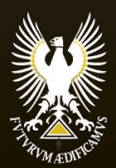




\title{
La enseñanza de la lectura como profilaxis: el Decreto Orgánico de Instrucción Pública: entre la caridad y la instrucción*
}

\author{
Diana Paola Guzmán Méndez ${ }^{1}$ \\ Universidad Jorge Tadeo Lozano - Colombia
}

Recepción: 23/10/2015

Evaluación: 21/04/2016

Aprobación: 26/05/2016

Artículo de Investigación e Innovación.

DOI: http://dx.doi.org/10.19053/20275137.5202

\section{Resumen}

El radicalismo liberal que gobernó los destinos nacionales entre 1863 y 1886, marcó el inicio de una nueva era para la educación en Colombia. Laica y gratuita, la enseñanza de la literatura ocupó un espacio central dentro del plan liberal. Educación, higiene y moral formaron una triada que definió de manera fundamental la concepción de la educación y la función de las letras como parte evidente del progreso y el desarrollo. Esta investigación intenta demostrar que la lectura se formuló como una profilaxis, una limpieza y una medicina preventiva que atravesó el tiempo y se instaló sobre dos lógicas más cercanas que enfrentadas: la de la caridad propia de la propuesta católica que se basa en los principios

\footnotetext{
* El presente artículo forma parte del proyecto de investigación «Caracterización de la enseñanza de la lectura en Colombia (1870-1950)», inserto en la línea de análisis del discurso adscrita al grupo Mente, lenguaje y sociedad del Departamento de Humanidades. Es apoyado en convocatoria interna por la Universidad Jorge Tadeo Lozano.

1 Doctora en Literatura. Profesora titular de Departamento de Humanidades y de la Maestría en Semiótica de la Universidad Jorge Tadeo Lozano. Correo electrónico: dianap.guzmanm@utadeo.edu.co
} 
lancasterianos y la lógica de la instrucción cifrada en Pestalozzi relacionada con la idea de una cuerpo nacional en vías del progreso. Los materiales de lectura que analizamos para este trabajo, demuestran que leer era una práctica moral antes que de educación y conocimiento.

Palabras clave: Decreto, profilaxis, lectura, cuerpo, caridad, instrucción.

\title{
The Teaching of Reading as Prophylaxis: the Organic Act of Public Instruction: between charity and instruction
}

\begin{abstract}
The liberal radicalism that governed national destinies between 1863 and 1886 marked the beginning of a new era for lay, free education in Colombia. The teaching of literature occupied a central space in the liberal plan. Education, higiene and morality formed the triad that fundamentally defined the conception of education and the function of literature and reading as elements of progress. This study attempts to demonstrate that reading was formulated as a prophylaxis, a method of higiene and preventive medicine that traversed time and was installed on two contradictory forms of logic: the sense of charity belonging to the catholic ideology, based on Lancasterian principles, and the logic of instruction based on Pestolazzi, related to the idea of a national body on the path of progress. The reading materials analyzed in this study demonstrate that reading was a moral practice before an educational and knowledge-related one.
\end{abstract}

Key Words: Act, prophylaxis, reading, body, charity, instruction 


\section{L'enseignement de la lecture comme prophylaxie: le Décret Organique d'Instruction Publique: entre la charité et l'instruction}

\section{Résumé}

Le radicalisme libéral qui a gouverné la nation entre 1863 et 1886, a marqué le début d'un nouvel âge pour une éducation laïque et gratuite en Colombie. L'enseignement de la littérature a occupé un espace central dans le plan libéral. Éducation, hygiène et morale ont formé une trilogie qui a résumé la conception de l'éducation et la fonction des lettres comme un élément du progrès. Notre recherche se propose de montrer que la lecture a été conçue comme une prophylaxie et comme une médecine préventive qui ont traversé le temps et se sont installés sur deux logiques plutôt proches que contradictoires: celle de la charité, consubstantielle au projet catholique fondé sur les principes lancastériens, et la logique de l'instruction fondée sur Pestalozzi et liée à l'idée du corps national dans les voies du progrès. Les matériaux de lecture que nous analysons pour ce travail, démontrent que lire était une pratique relative à la morale plutôt qu'à l'éducation et la connaissance.

Mots-clés: Décret, prophylaxie, lecture, corps, charité, instruction.

\section{Introducción}

La enseñanza de la lectura siempre ha sido un punto neurálgico en los proyectos políticos y sociales de diferentes periodos de la historia nacional; de hecho, la preocupación por la formación del lector, surge desde la dinámica dicotómica entre la Iglesia y el Estado que ha caracterizado la historia del país. Si bien no es nuestro interés central enunciar de forma detallada dicha relación, si es un escenario ideal para describir la representación de un lector que se configuró como el caballo de batalla entre el clero y el gobierno. El Decreto Orgánico de Instrucción Pública promulgado en 1870, es tal vez la muestra 
más interesante de una lucha por la supremacía de uno y otro poder sobre la educación. Este decreto organizó las escuelas primarias y estableció tres escenarios de acción: la instrucción, la inspección y la administración.

En el texto del decreto, el Estado no solo se reconoce como instrumento central del bienestar común, sino que acoge como propia la responsabilidad sobre las instituciones de salud y educación. Es así como la salud y la educación ocupa una misma normatividad y se convierten en sinónimos. En consecuencia, la consigna de educar para la salud y ser sano para educarse, es una línea conceptual cuyo objetivo no es otro que institucionalizar un orden discursivo sistematizado y exterorizado a través de prácticas determinadas ${ }^{2}$.

De acuerdo con Fairlough este proceso de normatización e institucionalización de los discursos deben contemplar la construcción de los significados ideacionales, es decir, el proceso genético en el que surgen las ideas y relaciones que los componen $^{3}$. Por esta razón, la idea de un Estado renovado es resultado de una serie de procesos que se evidencian de forma transversal y permanente en el uso de las categorías dentro de los discursos oficiales y científicos; así, por ejemplo, el Estado se presenta como protector y garante de las leyes nacionales en el Artículo 19 de la constitución de 1886; en este mismo año, a través de la Ley 30, se constituyen las juntas de higiene que deben velar por la salud y la limpieza física y moral de la población.

El gobierno expresaba su preocupación constante por una salud más preventiva que curativa y comenzaba su escalada para erradicar enfermedades que afectaban a las regiones

2 Cuando hacemos referencia a los órdenes discursivos partimos de la concepción de Norman Fairclough. Para este autor el discurso es un uso lingüístico concebido como práctica social. En esta medida, el discurso se institucionaliza al normatizarse de forma colectiva y al regular los procesos de representación, significación y experiencia. Es así como el discurso sobre la higiene se institucionaliza a través de las prácticas de salud y prevención y media la representación del individuo y su cuerpo a través de una presencia capital del progreso y su desarrollo.

3 Norman Fairlough, Language and power (New York: Longman, 2001), 101. 
intranacionales. Sin embargo, el discurso sobre la salubridad entrañaba otros tonos y otras intenciones, la promulgación de la limpieza y las prácticas corporales correctas, se orientaba también a una higiene mental y moral, heredera de la tradición católica y ultramontana que ha caracterizado la dinámica histórica de Colombia.

La labor de dichas juntas era vigilar e inspeccionar la moralidad, la seguridad y la salubridad públicas. La enunciación de la ley es un reflejo de la tríada inseparable entre moral, salud y seguridad que ha estado presente a lo largo de la historia nacional. Sin embargo, en el siglo XIX, esta unión parece ser aprobada e institucionalizada por la propia Constitución. De hecho, años antes de la Carta Magna de 1886, las publicaciones periódicas ya proponían una unión entre la salud y el cumplimiento de los preceptos católicos como el de la caridad. El 24 de septiembre de 1864 se publica el primer número de La Caridad. Lecturas del hogar, en su prospecto se lee claramente que

[...] escribimos para todos los corazones generosos, suplicándoles vengan a socorrer a la niñez desvalida y enferma que carece del suave calor del seno de una madre; a la ancianidad agobiada por las enfermedades; a esas pobres mujeres acuchilladas por el dolor, que ven agonizar a las prendas de su alma transidas de frío, pálidas de hambre, sin vestido, sin lecho y con enfermedad ${ }^{4}$.

De hecho, resulta necesario destacar que las publicaciones periódicas católicas que abundaron en la segunda mitad del XIX, volcaron su mirada a las mujeres y a los niños como sujetos perfectos de la prevención y de la formación de un acervo católico perdurable, no en vano la primera sección dedicada a los niños ve la luz en 1849 y forma de este mismo periódico ${ }^{5}$.

4 José Joaquín Ortiz, «Prospecto», La Caridad. Lecturas del hogar, n 1 (1864): 2.

5 De un modo u otro, el discurso de la prevención se enlaza con un discurso axiológico y moral que tiene su origen en la Europa decimonónica. La vinculación de las ideas sobre la higiene con los derroteros de la eugenesia, encuentra su base en la concepción de prevención que nacía en la centuria del XIX en Inglaterra y Francia. 
Si regresamos a Fairlough, para comprender la relación entre educación e higiene que se expresa de manera determinante durante la República Liberal, es necesario comprender las bases que consolidaron estos vínculos. Como es bien sabido, la relación entre enfermedad y pobreza, entre enfermedad y decaimiento racial es de larga data. De acuerdo con Jason McGraw, el periodo subsiguiente a la Guerra de los Mil Días (1899-1902) determinó un debate eugenésico que situaba como parte de los problemas de la nación, la procedencia geográfica y fenotípica de los pobladores de algunas regiones del país; por tanto, pensar la raza era esencial para alistar el terreno de un progreso que se presentaba inminente ${ }^{6}$. Sin embargo, la influencia del movimiento higienista europeo de mediados del siglo XIX, marcó en el país un presupuesto que, incluso, fue tenido en cuenta en la Constitución de $1886^{7}$.

Un elemento que queda claro en el orden legal de la higiene, es la consolidación de la triada conformada por limpieza, moral y educación; un punto que va a ser común en el devenir temporal, es que la higiene no es solo una práctica exterior, sino que es función de la educación: estar limpio por fuera debe significar estar limpio por dentro. En este sentido, la idea de prevención que llega a Colombia con los principios de Henry P. Stearns a través de las escuelas lancasterianas, convierte a la instrucción pública en bastión que asegura las prácticas higiénicas y, que además, las trasmite por medio de la enseñanza.

Con el arribo de los principios de Pestalozzi a la educación colombiana, se entroniza la idea de una educación integral en donde cuerpo, mente y alma son una sola unidad, la necesidad de limpiar la mente para, que a su vez el cuerpo y el alma

6 Jason McGraw, «Purificar la nación», Revista de Estudios Sociales, n 27 (2007).

7 Por ejemplo, 1833 se publica un texto que resulta revelador. Se trata de Preceptos útiles sobre la conservación de la salud, y la asistencia de los enfermos mandados imprimir i enseñar en las escuelas de primeras letras de niños de ambos sexos de la Provincia de Bogotá por el Gobernador de ella, Dr. Rufino Cuervo. Estos principios mencionan no solo los cuidados sobre el cuerpo a través de la limpieza y la higiene, sino también la relación entre educación y buenas prácticas. En este texto aparecen los tres primeros puntos de lo que luego será el decálogo de la higiene que se publicó como ordenanza para las escuelas hacia 1910. 
estuvieran incólumes, requería de dinámicas educativas muy concretas. De hecho, el principio del ser integral que expresó Pestalozzi, se consigna y legitima en 1870 a través del Decreto Orgánico de Instrucción Pública, en donde se explicita la influencia de Pestalozzi en el artículo 30: "La enseñanza en las escuelas no se limitará a la instrucción, sino que comprenderá el desarrollo armónico de todas las facultades del alma, de los sentidos i de las fuerzas del cuerpo"8. Esta caracterización de la educación integral, trae a colación un elemento que, dentro del modelo lancasteriano, había quedado excluido: los cuerpos se convierten en objetos de la intervención educativa ${ }^{9}$.

El decreto de 1870 que rigió los destinos de la educación hasta 1932 cuando la República Liberal hizo cambios y transformaciones en la ley educativa a través del Decreto 1487, estaba basado en los principios de la enseñanza objetiva proclamada por Pestalozzi; por esta razón, en dicho decreto hay una presencia permanente de la educación sobre los cuerpos, ya que, para Pestalozzi, el aprendizaje del niño comenzaba por su relación exterior y sensorial con el mundo y culminada en la conformación de una interioridad limpia y moral ${ }^{10}$. Incluso, para Pestalozzi la cadena que estructuraba al sujeto integral, y que se conformaba por la moralidad, el hacer y el conocer, presenta un orden determinado: la observación del mundo se conforma como un vehículo para la relación del niño con el mundo y con su corporeidad; es decir, la moral se siente. De este modo, el niño hace con moral y aprende con moral, el

8 "Artículo 30», Decreto Orgánico de instrucción pública, (1870), 3.

9 En el artículo 35 del mismo decreto se instaura la enseñanza de «La jimnástica i calisténica, como parte indispensable de un sistema completo de educación». A los colegios masculinos se les exigía instrucción militar. En el horario que registra el decreto para las escuelas, aparecen tres horas semanales dedicadas a la instrucción de la higiene. Curiosamente superan las horas de religión (que no eran obligatorias) y se dictan seguidas de las clases de moral.

10 El Decreto Orgánico de Instrucción pública sufre varias modificaciones, en 1892 el plan Zerda retorna poderes a la Iglesia y hace hincapié en la educación religiosa; sin embargo, la división de la instrucción pública sigue siendo la misma que propuso el decreto y, que a pesar del marco regeneracionista, dichas modificaciones no fueron tan profundas como podía esperarse. Es hasta 1932 con el decreto 1487 firmado por el entonces presidente Enrique Olaya Herrera que se hacen reformas sustanciales y se involucran nuevos enfoques pedagógicos como los de Decroly o Montessori. 
cuerpo es instrumento para construir al ser interior limpio y no exclusivamente para ser objeto de políticas de restricción.

El presente artículo hace referencia a la triada entre educación, moral y salud que establece el Decreto Orgánico de Instrucción pública promulgado en el Olimpo Radical (18631886) y, que además, influyó en las políticas educativas de la República Liberal. La enseñanza de la lectura vista a través de la publicación oficial de la Secretaría de Instrucción Pública, La Escuela Normal, más las citolegias y los manuales de lectura aprobados por el Estado en el radicalismo liberal del XIX, constituyen el corpus de análisis de este trabajo. De igual modo, la relación entre la lectura y el cuerpo que se evidencia a través de la pedagogía de Pestalozzi, propone no solo una concepción de la nación como cuerpo, sino de la lectura como profilaxis.

\section{Enseñar a leer, aprender a leer: las letras como profilaxis}

Desde la perspectiva del ser integral propuesta por Pestalozzi, columna vertebral del decreto de 1870, todos los cursos y los campos de aprendizaje son, necesariamente, prácticas corporales. La enseñanza de la lectura, es, sin lugar a dudas, uno de los escenarios más visitados y nombrados por estos principios. En 1897 se publica, con Licencia Eclesiástica, Lectura infantil para la enseñanza primaria de Eva Barco, el libro va con un pequeño texto del Presbítero y educador Pablo Manuel Bernal quien alaba el trabajo de Barco y lo relacionaba con los principios pestalozzianos: "Su trabajo es uno de los más ajustados a los principios pedagógicos implantados por Pestalozzi (...) sobre todo, esta idea nueva y fecundísima en resultados de consonantación en la lectura rudimentaria" ${ }^{11}$.

Como lo menciona Néstor Roberto Cardoso, la aparición del texto escolar y su propagación a través de las políticas del gobierno, genera una relación muy cercana entre el libro y el lector; además, fija los órdenes discursivos que representan de

11 Pablo Manuel Bernal, introducción a Lectura infantil para la enseñanza primaria, de Eva Barco (Bogotá: imprenta La Luz, 1870), 1. 
manera sistematizada los roles sociales que el niño-lector ha de cumplir en una sociedad de raigambre cristiana ${ }^{12}$. El hecho de que Eva Barco, en la introducción de su libro plantee un mecanismo de aprendizaje que involucra el sentido de la vista y el oído, convierte esta actividad en una dinámica corporal:

Así, pues, cuando el institutor quiera desarrollar una letra ó una sílaba, presentará á la vista de los niños el dibujo de un objeto cuyo nombre contenga. Al principio el sonido de la letra ó de la sílaba que quiere desarrollar. Esto ayudará al niño a relacionar, como lo propone el maestro Pestalozzi, el mundo con lo que lee y con lo que se siente ${ }^{13}$.

Pero antes que Eva Barco implantara los principios de la enseñanza objetiva de Pestalozzi, Rufino José Cuervo había pensado en un alfabeto imaginario creado a través de números e imágenes; es decir, cada letra tenía un número y una imagen que la caracterizaba; así, por ejemplo, la B tenía el número 2 y una imagen de ballena o la $\mathrm{E}$ el número 13 y un elefante; este proyecto de 1880 nunca se publicó pero si circuló de manera restringida. En 1891 llega a Colombia La Citolegia. Método de lectura practica sin deletrear; desde la introducción se deja claro que la llamada citolegia es un método de lectura que emplea alfabetos, cuadros y ayudas visuales. Esto quiere decir que los colombianos que aprendieron a leer con las citolegias, aprendieron a leer con todo el cuerpo. En esta edición de 1891 y en la publicada en 1950 por la librería Bedout, se leen las ventajas de este método:

Ella tiene también la ventaja de seguir con exactitud rigurosamente lógica el método analítico de comenzar por lo más fácil y seguir gradualmente á lo más difícil; de modo que si el maestro sabe hacer buen uso de los cuadros, insensiblemente se desarrollarán las facultades intelectuales de sus discípulos, y al concluir la octava clase sabrán leer, y entenderán lo que han leído ${ }^{14}$.

12 Néstor Roberto Cardoso, Los textos escolares en Colombia: dispositivos ideológicos (Ibagué: Universidad del Tolima, 2007): 25.

13 Eva Barco, Lectura infantil para la enseñanza primaria, (Bogotá: Imprenta La Luz, 1870), VI.

14 Citolegia: nuevo método de lectura practica sin deletrear para uso de las escuelas primarias (Bogotá: Librería Colombiana Camacho Roldán y Tamayo, 1891), 4. 
Lo propio hará la citolegia citográfica escrita por Martín Restrepo Mejía y publicada en 1917 por la tipografía de Castellanos y Ruíz. Las citolegias tienen una característica común, traen los ejercicios que el maestro deberá realizar en clase para que el estudiante pueda hacerlos en su casa. Tanto en 1891 como en 1917 o 1950, estos materiales contienen en un cuadro anexo ejercicios análogos a los que el instructor realiza en la escuela. Esta condición convierte a las citolegias en materiales muy interesantes, por un lado, los ejercicios evidencian un orden en el uso de los sentidos: ver, escuchar, relacionar; por otro, en la citolegia de Restrepo Mejía, los ejercicios de lectura se intercalan con imágenes que traen a niños en la actividad de leer o haciendo ejercicio, incluso propone pausas activas de calistenia.

Otro elemento común de las citolegias es la relación entre el material de lectura y la moral. Si bien en el caso de Eva Barco se subraya el hecho de que el libro tiene licencia eclesiástica, en las citolegias los preceptos morales parecen en lo ejemplos que se consignan para que los niños aprendan las primeras letras ${ }^{15}$ : "Wenceslao Wilches, es un niño muy desaplicado. A veces, en vez de ir a la escuela, se va a rodar calles. Pero sus padres lo hacen prender de un policía, y él pasa la vergüenza de ser llevado a la escuela como un criminal"16.

Pero es necesario aclarar que no es posible determinar el modo como los estudiantes leían o se les enseñaba a leer exclusivamente por medio de los textos que sirvieron como primer recurso; para Karin Littau, por ejemplo, la lectura, en

\footnotetext{
15 La cita del niño que no va a la escuela y es apresado, es reflejo de las leyes contra la vagancia en Colombia. Dichas leyes son numerosas y permanecieron hasta bien entrado el siglo XX, la más rigurosa fue la Ley del 3 de mayo de 1826 en donde se define a los vagos como un peligro social y se les castiga con cárcel y hasta con el exilio. Esta ley permanece en la normatividad educativa, incluso, el decreto de 1870 considera la educación obligatoria y enuncia como perentorio que los niños que se encuentren en la calle fuera del horario permitido y no porten el uniforme, sean ser llevados a la cárcel hasta que sus responsables hicieran presencia. Para profundizar sobre el fenómeno de la vagancia ver: Natalia Botero Jaramillo, «El problema de los excluidos. Las leyes contra la vagancia en Colombia durante las décadas de 1820 a 1840", Anuario Colombiano de Historia Social y de la Cultura, nº 39 (2012): 47.

16 Martín Restrepo Mejía, Citolegia citográfica por la cual se enseña rapidamente a leer y a escribir (Bogotá: Tip. del Externado, 1917): 57.
} 
tanto aprendizaje y enseñanza, está moldeada por el contexto que la rodea y que determina la vida de las personas ${ }^{17}$. Es así, como el ejemplo que citamos anteriormente solo puede ser comprendido a través de los principios legales que convertían la "vagancia" en un delito. Es de esta manera, como queda claro que la escuela cumplía un papel de limpieza y de seguridad colectiva, y que el decreto de 1870, era el derrotero para que esto ocurriera.

De hecho, el mismo Decreto Orgánico de Instrucción Pública, está estructurado de tal forma que cada procedimiento y cada ley, configura un espacio de limpieza, seguridad y organización. Como lo refiere Maurice Agulhon, los procesos de vinculación entre la enseñanza y la sociedad han de determinarse a través de circuitos de sociabilidad que complementan, a su vez, las fisionomías de las instituciones; en este caso, la educación ha de ser vista como una institucionalización y regulación de prácticas de enseñanza cuya fisionomía ha de ordenarse a partir de su legislación ${ }^{18}$.

Es así como la fisionomía de la enseñanza de la lectura debe evidenciarse a partir de dos principios que Agulhon considera centrales: la creación de espacios de aprendizaje y lectura como las bibliotecas o los salones, junto con la aparición de dinámicas que contabilicen a los sujetos inmersos en el circuito de sociabilidad. El decreto de 1870 contiene ambas condiciones. Este documento no solo determina la división escolar, sino las funciones de los instructores, directores e inspectores; además, en la sección segunda, Artículo 10, se estipula la creación de un órgano impreso que cumpliera las veces de puente entre el Estado, los instructores y los estudiantes: "La Dirección jeneral publicará hasta dos veces por semana, i en los días que ella determine, un periódico que

17 Karin Littau, Teorías de la lectura libros, cuerpos y bibliomanía (Buenos Aires: Manantial, 2008): 42.

18 Maurice Agulhon, El círculo burgués; seguido de una pequeña autobiografía intelectual (Buenos Aires: Siglo Veintiuno Editores, 2009): 101. 
se titulará La Escuela Normal, el editor es Secretario de la Dirección"19.

La Escuela Normal (1871-1880) fue la publicación oficial de la Secretaria de Instrucción Pública, allí salió a la luz el Decreto Orgánico completo, además de todos documentos legales, cartas y lecciones de clase que debían ser empleadas en las aulas nacionales. Esta revista cumple con la función de determinar un grupo de lectores específico, que, además, han de cumplir las reglas y principios que se explicitan en sus páginas. Por otra parte, en 1872 , comienzan a publicarse una serie de censos sobre los niños y niñas que asisten a las escuelas y que los organizan en regiones, sexo y edad; como resultado los agentes que conforman este circuito de sociablidad son instruidos de acuerdo con dicha clasificación ${ }^{20}$.

En términos de Norbert Elías, estos escenarios de clasificación, normatividad y cuantificación se reflejan en el control estatal de las prácticas, las emociones y los cuerpos ${ }^{21}$. Por ejemplo, el 4 de mayo de 1872, La Escuela Normal publica, anuncia con bombos y platillos, la aparición y adopción del Tratado teórico i práctico de jimnasia (1870), adoptado como texto oficial en el sistema de escuelas públicas, específicamente las de Santander y Boyacá escrito por M. Luis Leonel. En la presentación que se hace del libro en La Escuela Normal se señala que la gimnasia como actividad diaria en los colegios tiene como propósito "dar fuerzas en lo moral y en lo físico, para contribuir al bien general; la prosperidad pública tiene su fuente en la de cada uno de sus miembros"22. Además, este tratado va a marcar permanentemente la unión entre cuerpo,

19 «Artículo 10», Decreto Orgánico de Instrucción Pública, La Escuela Normal, n 1 (1870): 3.

20 Otro elemento importante que se encuentra como función de La Escuela Normal es su responsabilidad como libro de texto. El 28 de septiembre de 1872, número 90 de la revista, se aprecia una nota que resulta de capital atención: el 26 de julio se decreta que todos los manuales y textos de aula empleados en las escuelas sean publicados en este periódico que se distribuía gratuitamente en el territorio nacional.

21 Norbert Elías, Deporte y ocio en el proceso de la civilización, (México: Fondo de Cultura Económica, 1995): 98.

22 «Presentación del tratado teórico i práctico de jimansia y calestenia», La Escuela Normal, $\mathrm{n}^{\circ} 70$, (1872): 398. 
mente y moral, pero lo interesante de este texto es que el saber también se vincula con el saber porque "[...] la aplicación mental es un poderoso remedio tanto para las enfermedades del cuerpo como para las del espíritu”23.

El tratado incluye no solo ejercicios físicos, sino lecturas edificantes y moralizantes, también una guía para sentarse correctamente y tener buenos modales. Esta guía estaba ilustrada con 50 figuras que combinan las posiciones corporales con los modales, incluso se encuentra una larga sesión de instrucciones para leer de "forma higiénica y correcta" ${ }^{24}$. Otro texto que empieza a publicarse en La Escuela Normal es De la educación intelectual, moral y física de Herbert Spencer. En las entregas que aparecen en la revista hay una especial dedicada a la relación entre higiene y aprendizaje, evidentemente, el núcleo de esta relación es la superposición entre higiene y moral. El cuerpo lee aquello que debe aprender y lo aplica a su cuidado, este escenario de regulación presenta la lectura como una suerte de profilaxis, de mecanismo de limpieza y protección.

42 años más tarde, en Semanario infantil la Niñez, vuelve a aparecer el mismo texto de Spencer, solo que en la reflexión con la que se abre la entrega y que está dedicada a los niños, se compara al niño que lee con un ser sano y al niño que no lee con un sujeto enfermizo:

El niño que lee, es similar al guerrero fuerte que se adereza convenientemente para entrar en la batalla, es fuerte, rozagante. Pero el niño vago y perezoso será incapaz de atender sus asuntos, debilucho y encorvado, no tendrá mucho tema del cual hablar ${ }^{25}$.

La relación entre la lectura y la fortaleza física deviene, evidentemente, del vínculo que autores como Spencer o Pestalozzi tuvieron en la vida intelectual y política colombiana.

23 «Presentación del tratado», 398.

24 «Presentación del tratado», 399.

25 Herbert Spencer «De la educación intelectual moral y física», La Niñez: semanario infantil Ilustrado, $\mathrm{n}^{\circ} 2$ (1914): 17. 
No en vano, el texto de Spencer se publica en un órgano estatal como La Escuela Normal ${ }^{26}$.

Otro colaborador frecuente de La Escuela Normal fue el presbítero Martín Lleras quien publica con Hotschick en 1872 El primer libro de lectura, también aparece entero en la revista Pedagogía, de los deberes particulares de los institutores $y$ cómo deben cumplirlos. En este texto, Lleras analiza las diferentes clases de pedagogía criticando fuertemente la lancasteriana y ponderando a Pestalozzi. Sin embargo, para Lleras el mejor método es "el denominado eurístico en donde el niño aprende a su merced a través de su cuerpo y de sus sentidos" ${ }^{27}$. En el número 103 publicado el 21 de diciembre de 1972, Lleras da a conocer su método de lectura y escritura que fija su atención no solo en los modos de aprendizaje, sino en los modos en los que el instructor debe marcar los tiempos de lectura saludables (que no deben superar los 80 minutos) y los grados de inclinación de las letras. En este mismo número, además, Lleras propone las medidas ideales y el modelo de pupitres que han de adoptar las escuelas públicas ${ }^{28}$.

Estos pupitres, que de acuerdo con Lleras han de ser individuales, generan y reafirman el modelo de lectura pestalozziano enfocado en la práctica individual y silenciosa que el estudiante debería llevar a cabo bajo la vigilancia cercana de su maestro. De acuerdo con Littau, la lectura individual abre la puerta a un individualismo que concibe un

26 Uno de los primeros manuales de puericultura traducidos en el país, reproduce gran parte del pensamiento de Spencer. Se trata de Manual de puericultura. Consejos á las madres para la crianza de sus hijos del Dr. G. Variot y publicado por la tipografía a vapor de Mogollón. Las menciones a Spencer son considerables, una de las más importantes es la hecha por el Dr. Jorge Bejarano, reconocido médico e higienista y además, primer ministro de higiene (1946-1947). El aún joven Bejarano escribe una serie de columnas sobre salud, higiene y prevención que se publican durante la década de 1920 en el periódico bogotano El Gráfico. En estas comunicaciones y además en las conferencias que dio Bejarano en el teatro Bogotá, aparece permanentemente la presencia de Spencer, principal defensor de la dupla entre moral y limpieza; entre instrucción y salud.

27 Martín Lleras, «Pedagogía, de los deberes particulares de los institutores y cómo deben cumplirlos», La Escuela Normal, n 101, (1872): 450.

28 Martín Lleras, «Método de lectura y escritura», La Escuela Normal, n 103 (1872): 455 . 
lector capaz de interpretar, desde su experiencia, aquello que ${ }^{l e e^{29}}$. Vale la pena recordar que la revista era entregada a las bibliotecas de las escuelas y se enunciaba su consulta y uso obligatorio de parte de los profesores y de los estudiantes.

En la Citolegia (1917) de Martín Restrepo Mejía, mencionada anteriormente, este modelo seguía conservándose. Por esta razón, los ejercicios que el maestro llevaba a cabo en clase se reproducían en la parte final de la página para que el niño los continuara en su casa. Esto deja entrever que los libros podían ser llevados a los hogares y que el estudiante pudo haber iniciado una relación íntima y constante con su material de lectura.

Otro factor que destaca de modo permanente Martín Lleras, es el hecho de que la educación del niño no se limita al espacio escolar, sino que es la familia el escenario más importante y el socio más estratégico en la formación de un ciudadano limpio y moral. Para Lleras, el ocio significaba el vicio, por eso, el llevar la lectura a la casa devenía en que el niño o el joven estaría ocupados en "buenos oficios de aprender y fortalecer su salud y su conocimiento, lejos de los vicios que el ocio atrae de por si" "30. El binomio que entrañaba el modelo higienista (salubre/insalubre) y de prevención promulgado por Henry P. Stearns, Spencer y Pestalozzi, atravesó de manera capital al Decreto Orgánico de Instrucción Pública, reproduciendo la concepción que se tenía de la lectura como una práctica salubre y preventiva.

Pero este modelo de salubridad, encarnaba la necesidad de marcar y determinar de modo más radical los roles entre instruido e instructor. Basta con ver un extenso texto que ocupa unos 6 números de La Escuela Normal, el trabajo publicado por entregas desde el 3 de agosto de 1872 en el número 83 y titulado "La instrucción popular", determina que la educación ha de ser igualitaria y que es labor de los letrados "provenientes de las ciudades y de los centros civilizados

29 Littau, Teorías de la lectura, 42.

30 Lleras, «Pedagogía, de los deberes», 452. 
ayudar a ver a los pobres el mundo del conocimiento" ${ }^{31}$. La educación, representada en la lectura, de nuevo aparece como elemento que previene revoluciones y levantamientos populares; de hecho, el texto afirma que si Francia hubiera tenido mayor atención en la instrucción de su pueblo habría evitado terribles derramamientos de sangre, pues "la plebe furiosa no se compone de hombres ilustrados, sino de gente sin cultura" 32 .

El modelo de la enseñanza como una actividad del Estado, garantizaba que este proceso propuesto por el radicalismo liberal se concretará y se desarrollará de forma satisfactoria. De acuerdo con Gilberto Loaiza Cano, el modelo instruccionista, lejos de significar la democratización de la educación, definía aún más las brechas sociales que caracterizaban la sociedad nacional. De hecho, para Loaiza Cano, el sujeto que merecía la mayor atención de Decreto de 1870 no es el estudiante sino el maestro, éste se erige como el cuerpo intervenido y preparado para que encarne el ideal liberal ${ }^{33}$.

\section{Cuerpos ideales: entre la lógica de la caridad y de la instrucción}

El 30 de agosto de 1872, La Escuela Normal publica una invitación para las señoritas que quieran ser instructoras en la normal que se abriría en el Estado de Cundinamarca. Dentro de los requerimientos exigidos se cuentan: tener 17 años, certificar pureza de costumbres y no tener ningún defecto físico que riñera con el oficio de la enseñanza ${ }^{34}$. De hecho, $L a$ Escuela Normal está llena de lecciones y textos dedicados al oficio de enseñar, a los ideales y a las condiciones que han de cumplir los maestros. Lo interesante de estas publicaciones es que desde el número 53 hasta el número 54 aparece un

31 «La instrucción popular», La Escuela Normal, n 83 (1872): 150. El subrayado es mío.

32 «La instrucción popular», 151.

33 Gilberto Loaiza Cano, «El maestro de escuela o el ideal liberal de ciudadano en la reforma educativa de 1870», Historia Crítica, n 34, (2007): 64.

34 «Invitación», La Escuela Normal, n 87, (1872): 222. 
texto llamado "Carta de un maestro de escuela" firmado por Romualdo B. Guarín, director de la escuela de varones de Villeta, esta carta resume en grandes rasgos los ideales que han de cumplir los profesores.

La virtud más importante es la pureza de costumbres, la moral evidenciada en las prácticas cotidianas; de hecho, una causal de despido es "las malas costumbres y las inmoralidades". Además,

[...] debe cuidar su presentación, ser limpio por dentro y por fuera, vestir bien y hacer ejercicio a diario. El oficio de enseñar exige que el físico esté incólume, que el maestro tenga buena estatura y apariencia modesta. El maestro debe evitar excesos, lo que se ve por fuera es lo que está sembrado adentro, él será el espejo que han de seguir sus jóvenes estudiantes ${ }^{35}$.

Como lo reafirma Loaiza Cano, el maestro de escuela resultó ser la suma de todas las virtudes que el radicalismo liberal pretendió difundir; sin embargo, estas cualidades debieron ser visibles, y no quedarse en el plano de la subjetividad, la moral atravesaba los cuerpos de los maestros. Este discurso de selección en donde se solicitaban maestros limpios y sanos, también evidenció la presencia de una higienización de la enseñanza. Los profesores tendrían que ser salubres, pues su principal misión era prevenir la enfermedad de la ignorancia y la barbarie.

En "Pensamientos sobre educación", texto completo que se publica por entregas en La Escuela Normal, se hace evidente que la bondad del corazón que el maestro debe tener, es, sin lugar a dudas, su principal virtud. Pero esta condición se vislumbra en la limpieza y en la buena salud: "[...] como lo explica el Dr. Spencer, el maestro debe ser tan limpio y bueno como su corazón y su virtud"36.

35 Romualdo B. Guarín, "Carta de un maestro de escuela», La Escuela Normal, n 54, (1872): 15 .

36 «Pensamientos sobre educación», La Escuela Normal, n 54: 15. 
Y este "arte de conservar la salud" se convierte en una cualidad de los maestros que debe propagarse como vacuna por todo el territorio nacional ${ }^{37}$. Si los maestros son los cuerpos modelos, los inspectores serán quienes garanticen este modelo, y los estudiantes los receptores que lo reproduzcan. La dupla entre el maestro y el inspector, será aquella que avale el control sobre los cuerpos y sus prácticas; una de las funciones principales del inspector es "garantizar condiciones salubres, las virtudes y los oficios de los maestros" 38 .

La triada entre educación, higiene y moral a la que nos referimos con anterioridad, vuelve a aparecer al mencionar las funciones de los maestros y de los inspectores. Como lo evidencia Olivia López Sánchez, en los proyectos de modernización del Estado que caracterizaron a los gobiernos de raigambre liberal en América, la virtud pasa de ser moral a ser física: es virtuoso aquel que posea la salud y sea capaz de trasmitirla ${ }^{39}$.

La enseñanza de la lectura como parte de las funciones principales de los maestros, no resultó exenta de esta condición; si bien hemos visto que los métodos adoptados por el Decreto se presentaban en franca relación con las políticas de prevención, el oficio de los maestros como los instructores de las primeras letras también se vieron atravesados por este derrotero. Es sabido que en 1872 llegó a territorio nacional una misión pedagógica alemana, este acontecimiento es registrado por La Escuela Normal en su número 106; la misión estaba conformada por 9 profesores alemanes repartidos en los Estados de Antioquia, Bolívar, Cauca, Magdalena, Panamá, Cundinamarca, Tolima, Boyacá y Santander.

37 «Pensamientos sobre educación», 16.

38 «Pensamientos sobre educación», 16.

39 Olivia López Sánchez, «La higiene popular dirigida a las mujeres-madres: estrategias de la cruzada médico-higienista en la sociedad mexicana del porfiriato", en Al otro lado del cuerpo. Estudios biopolíticos en América Latina, comp., Hilderman Cardona y Zandra Pedraza (Medellín: Universidad de Medellín, Departamento de Ciencias Sociales y Humanas, 2014): 164. 
De acuerdo con la noticia publicada en la revista, la misión principal de estos maestros era la de fundar, en cada uno de los estados, una escuela normal y una elemental con el modelo prusiano. Este modelo estaba destinados a

[...] formar ciudadanos y trabajadores intelijentes, sanos y responsables para servir al progreso jeneral. Instruirán a los estudiantes y profesores en las materias básicas y en la salud de la prevención, pues los maestros también tendrán que trabajar con otros funcionarios del gobierno ${ }^{40}$.

Pero la noticia no se limita a nombrar las condiciones de permanencia y las funciones que llevarían a cabo estos profesores, también se enumeran los materiales de enseñanza que traen consigo y que pertenecen a la firma francoalemana Casa de Hachette \& Compañía ${ }^{41}$. Esta firma trae consigo "materiales que fundamentan lo más reciente en la ciencias y todos los textos se refieren a las manufacturas y a la formación de trabajadores para el progreso" ${ }^{42}$. Es claro que la función de una educación con estos principios se enfoca a la formación de una mano de obra que beneficie la modernización liberal; sin embargo, no todos los materiales se reparten de la misma manera, los pianos, por ejemplo, se llevan a las escuelas ubicadas en Cundinamarca y Santander, mientras que los mapas políticos, los libros sobre agronomía y demás insumos que hacen referencia al trabajo práctico, se llevan a las escuelas en Boyacá y Cauca; es allí en donde "los libros que enseñan los oficios básicos deben estar" ${ }^{43}$.

El material que sí se distribuye de manera común son los libros de lectura, encabezando el escrito por Martín Lleras y Hotschick y que cuenta con 4000 ejemplares, la gramática de César Guzmán tendrá el mismo número, pero los cuadros de citolegia con los silabarios contará con 16.000 unidades

40 «Los profesores alemanes», La Escuela Normal, n 106, (1873): 11.

41 De acuerdo con el informe, la Secretaría de Instrucción invierte 800 pesos para cada escuela, el inventario incluye materiales de laboratorio, 5 pianos con sus partituras, espejos parabólicos y una serie de adminículos tecnológicos.

42 «Los profesores alemanes», 12.

43 «Los profesores alemanes», 15. 
repartidas por todo el territorio nacional. El gobierno liberal depositó una confianza considerable en la misión alemana y en los materiales de la casa Hachette; sobre sus espaldas pesaría el cometido de formular un modelo de progreso y salud en las escuelas del territorio. Además, con la misión alemana llega una iniciativa que reafirma la analogía entre el modelo higienista de Henry P. Stearns y Spencer y el modelo pedagógico de Pestalozzi: las bibliotecas circulantes.

Estos espacios de multiplicación del conocimiento son "el natural complemento de la provisión de textos, i que está ordenado igualmente por encargo de la nación" ${ }^{44}$. En este sentido, las dinámicas liberales exigían mayor rapidez y eficacia en los procesos de la enseñanza, las bibliotecas circulantes son un ejemplo de este conocimiento que se va moviendo como una caravana de salud, de pueblo en pueblo vacunando contra la ignorancia y curando la enfermedad de la barbarie. Las bibliotecas que se mueven se describen como espacios vigilados, limpios y regulados: “[...] han de estar con mucha luz, con sillas suficientes, debe tener agua para lavarse las manos y evitar pasar suciedad, los libros deben cuidarse y permanecer limpios como los lectores que los quieran” ${ }^{45}$.

Libros, profesores y lectores deben permanecer limpios para que las bibliotecas sigan conservándose como escenarios salubres; de hecho, en el reglamento que establece el Decreto en el Artículo 14, es necesario que estos espacios sean adecuados y aseados porque tienen "el objeto de fomentar la aficion a la lectura, i dar aliento al trabajo en todas las clases sociales"46. Las bibliotecas circulantes "dan aliento", curan y crean hábitos permanentes. Pero vale la pena aclarar que esta "medicina" debe darse a través de dosis moderadas y lentas.

Como muestra de ello, la secretaría pone a prueba varios métodos de lectura que no se instauran por ser ineficientes. Ese es el caso de Método típico de enseñanza primaria para

44 «Los profesores alemanes», 15.

45 «Los profesores alemanes», 16.

46 «Artículo 14», Decreto Orgánico de Instrucción Pública, (1870), 8. 
la lectura y la escritura escrito por Ramón Mercado en 1872, la respuesta de los expertos (Dámaso Zapata, Santiago Pérez, Martín Lleras, Jil Colunje y el alemán Gotthold Weis). Todos consideraron que la propuesta de Mercado era inoperante primero por rápida (de acuerdo con Mercado en 45 días aprenderían a leer y a escribir correctamente) y segundo, por mecánica. Así lo expresa Santiago Pérez:

Los métodos rápidos no son de mi gusto. Comienzo por recordar que en salud, por ejemplo, cuando se intenta curar una enfermedad no siempre el método más rápido es el mejor. Pero el arte de leer es un remedio que debe aplicarse lento y no mecánico ${ }^{47}$.

Estos diagnósticos que se encuentran a lo largo de la Escuela Normal, no solo hacen referencia a los métodos de lectura que se presentaban para ser elegidos por la Secretaría de Instrucción, sino que se concentraban en los modos cómo los maestros deberían dictar sus clases de lectura. Lo interesante es que en las reflexiones que hace Martín Lleras, el cuerpo del instructor siempre está presente; así por ejemplo en "Pedagojia", Lleras propone que le profesor cuide su voz, que reciba orientación para poder modular correctamente y cumplir con las reglas de elocución: "[...] para que el maestro pueda cumplir con la elocución correcta y leer en voz alta, ha de cuidar lo que come, no tomar bebidas heladas ni hirvientes, no fumar y hacer buches con sal como lo recomienda el manual de higiene" ${ }^{48}$.

La voz que lleva la batuta durante la lectura en voz alta, debe también ser modelo de salubridad y armonía; de acuerdo con Lleras, la lectura dirigida por el maestro es el modelo para la lectura que harán luego los estudiantes en sus casas y sin dirección; es decir, la lectura individual. Como lo hemos dicho anteriormente, la lectura solitaria, sin dirección, constituye un paso importante en la conformación del sujeto, una suerte de emancipación, moderada claro está, del lector. Pero al

47 Santiago Pérez, «Método típico», La Escuela Normal, n 108, (1873): 29.

48 Martín Lleras, «Pedagojia. De la lectura en las clases superiores», La Escuela Normal, $\mathrm{n}^{\circ} 106,(1873): 37$. 
regresar a Lleras, es claro que dicho ejercicio de autonomía no es otra cosa que el resultado de un modelo corporal que surge de la idea de lectura dirigida, modulada y organizada por el maestro. Su voz, pausas (todas marcadas por Lleras en su texto) y elocuencia, servirán de sistema modélico, de corporización y encarnación de lo salubre ${ }^{49}$ :

Los signos como el punto deberán tener una pausa corta, paréntesis una especie de depresión más larga. La voz ha de bajar su tono, así el estudiante comprenderá mejor lo que lee y recordará la voz de su maestro cuando no esté con él ${ }^{50}$.

El maestro será el cuerpo de la nación y la lectura la práctica más higiénica, profiláctica y preventiva. El enseñar a leer con moderación, como lo expone Lleras, con tono bajo, con pausa, corresponde a un modelo de la educación que más que cultivar individualidades, se enfocaba a estructuras ciudadanos mansos, mano de obra contundente que pudiera servir al progreso de la nación.

El Decreto Orgánico de Instrucción Pública es, en sí mismo, un mapa de lo salubre (la educación dirigida por el Estado) y lo insalubre (la educación retardataria de la Iglesia). Era necesario que aquellas prácticas privadas del aseo, el cuidado del cuerpo y la lectura, que periódicos católicos como La Caridad. Lecturas para el hogar consideraba privadas y que debía hacerse en la "intimidad del hogar, bajo la voz generosa del padre o del sacerdote" ${ }^{1}$, se convirtieran en actos públicos, regulados, vigilados y protegidos por el Estado.

La lectura ya no solo era un acto moralizante y "positivo que bien dirigido puede engrandecer el alma y acercarnos a Dios" ${ }^{2}$, sino una acción que se hace con el cuerpo, con la voz y con todos los sentidos. Resulta interesante constatar

49 De hecho, dentro de las materias obligatorias cursadas por los jóvenes que se preparan para ser maestros estaba la de elocuencia, principios de higiene e instrucción física.

50 Lleras, «Pedagojia. De la lectura en», 37.

51 «Consejos para el pueblo», La Caridad. Lecturas de hogar, n 8: (1864): 117.

52 «Consejos para el pueblo», 117. 
la fuerte oposición de los sacerdotes rurales a las escuelas públicas, de hecho, en La Escuela Normal hay varias cartas de Inspectores de Instrucción que refieren casos específicos. Las más numerosas vienen de Boyacá y hacen referencia a que

[...] la tenaz oposición de los ministros del culto a las escuelas, hace que los sacerdotes castiguen a quienes asisten a la escuela con la negación de los sacramentos. Desde el pulpito dicen que las escuelas del gobierno propagan la enfermedad y que quieren sacar a Dios de la patria ${ }^{53}$.

Así se encuentran múltiples comunicaciones en donde la Iglesia se opone a los modos de educación del Estado por considerarla inmoral y escenarios insanos que propagan la enfermedad. Pero las repuestas de la secretaría a estos reparos eclesiásticos, también consideran la educación religiosa como retardataria y un "obstáculo para el progreso y el crecimiento sano de las mentes" $"$.

La disputa se concentra de nuevo en el binomio de lo salubre e insalubre, pero además, ambos bandos tratan de mantener el control sobre los sujetos a través de la regulación de su educación. Es evidente que la educación, términos de Ann Marie Chartier, se corporiza como enfermedad o salud, como herramienta que mantiene la legalidad de los acervos ideológicos. En espacios de conflictos muy agudos, aquellos poderes que se presentan como simbólicos, deben encarnarse en significantes que puedan ser regulados de manera directa ${ }^{55}$.

Como lo explica Ricardo Arias, el periodo del radicalismo liberal se caracterizó, como es bien sabido, por un anticlericalismo que comenzaba por atacar los territorios que la Iglesia había declarado como suyos; la educación fue, sin lugar a dudas, el caballito de batalla de la pugna entre clero y

53 Director de Instrucción Pública del Estado de Boyacá «Informe», La Escuela Normal, n 104: (1872): 409.

54 «Respuesta», La Escuela Normal, n 104, (1872): 411.

55 Ann Marie Chartier y Jean Hebrard, Discursos sobre la lectura (1880-1980), (Barcelona: Gedisa, 2005), 150. 
gobierno ${ }^{56}$. Es así como, regresando a Chartier, la enseñanza de la lectura puede ser el remedio o la misma enfermedad que se encarna en el cuerpo sano de la nación.

\section{Conclusiones}

Los dos modelos de enseñanza, la Iglesia que seguía los parámetros lancasterianos o el Estado bajola guía de Pestalozzi, se cifran sobre lógicas que parece diferentes pero que en realidad tienen más puntos de encuentro que antagonismos. Por un lado, el clero se situará bajo la lógica de la caridad, la educación es un "servicio que hace menos miserable la vida de los pobres. Enseñar al que no sabe, significa que el ignorante puede cumplir los designios de Dios" ${ }^{57}$. Por otro, el Estado se situará bajo el sistema de la instrucción, la educación como herramienta práctica y fija en la formación de ciudadanos útiles al progreso de la nación.

La lógica de la caridad o el modelo de la instrucción tienen puntos de encuentros que se sitúan, precisamente, en la concepción de lectura; incluso, en la representación de los lectores como cuerpos que reciben la medicina para la inmoralidad o para la ignorancia. José Emilio Burucúa propone que la representación del otro, es, en realidad, una explicación del otro, de este modo, el lector controlado, el cuerpo guardado de la peste liberal, no es otra cosa que una definición ideal del cuerpo nacional que el clero defendía; en el caso del Estado, ese cuerpo que lee solo, no es más que un lector configurado para servir al desarrollo de la nación ${ }^{58}$. Ambas representaciones, centradas en un lector controlado, guiado e instruido, preservan el binomio de lo salubre/insalubre.

De esta manera, los cuerpos-lectores en ambos sistemas, marcan una relación entre prácticas de lectura y roles sociales

56 Ricardo Arias, El episcopado colombiano: intransigencia y laicidad 1850-2000, (Bogotá: Ediciones Uniandes, Instituto Colombiano de Antropología e historia, 2003), 75 .

57 «Consejos para el pueblo», 118.

58 José Emilio Burucua, «La mentalidad de las élites sobre la violencia en Colombia (1936-1949)», Análisis político, nº 29, (1996): 100. 
direccionada por la imagen de un lector ideal que configura el cuerpo nacional ideal. La noción de un lector recién llegado como los niños y las mujeres (más tarde los obreros) es legítima en la medida que los poderes que controlan los medios de difusión definen las categorías de representación.

En consecuencia, las prácticas lectoras propuestas no se limitan al ejercicio mismo de la lectura o del aprendizaje esencial de las primeras letras, sino que están conectadas, por un lado, a un plan estatal ligado a la unión nacional $\mathrm{y}$, por otro, a la protección del legado y de los intereses católicos que, en apariencia, perdían terreno. De este modo, la lectura, es en realidad, una práctica axiológica y una apuesta de representación; no en vano, durante la República Liberal, heredera del legado de 1870, los cuerpos saldrán de las palabras y ocuparán la imagen, luego las ondas sonoras (radio Sutantenza). Al parecer, la pugna por la educación y la enseñanza de las letras, se convirtió en un problema centrado en el poder de la representación, de los cuerpos cifrados, más que de cambios sustanciales en los sistemas. La lógica de la caridad y de la instrucción permaneció debajo de las pieles representadas.

Vale la pena aclarar que si bien la lógica del instructor y del instruido, del orientado y del orientador perdura en proyectos como los de radio Sutantenza, la representación visual de los lectores que habitan las páginas de las cartillas que se repartían en los pueblos o las ilustraciones de la Revista Rin-Rin (1936-1938) editada por el Ministerio de Educación, ofrecen una giro visible de estas lógicas. El trabajo de Sergio Trujillo se enfoca, especialmente, en figuras de lectores que leen bajo los árboles, con ropa ligera y que parecen felices de su momento de lectura.

Sin embargo, en la revista Rin-Rin y en las cartilla de la escuela Sutatenza, los roles sociales son ampliamente marcados, se aprende a leer para limpiarse de la ignorancia y servir al campo colombiano. De hecho, en las actas de La Acción Católica Popular se verifica que su objetivo principal es instruir en lo práctico y enseñar en lo moral; enseñar a leer es 
una obra de caridad, pero, a su vez, de desarrollo y progreso. Es por esto que la Escuela de Sutatenza es la conjunción perfecta de las dos lógicas (caridad e instrucción), el cuerpo del campo es el cuerpo perfecto para empezar de nuevo, un cuerpo virgen y listo para la orientación ${ }^{59}$.

\section{Fuentes Documentales}

\section{Artículos de La Escuela Normal}

Director de Instrucción Pública del Estado de Boyacá. «Informe», $L a$ Escuela Normal, n 104, 18 de diciembre de 1872, 409.

«Invitación», La Escuela Normal, n 87, 30 de agosto de 1872, 222.

Guarín, Romualdo B. "Carta de un maestro de escuela», La Escuela Normal, $n^{\circ}$ 54, 13 de enero de 1872, 53-56.

«La instrucción popular», La Escuela Normal, n 83, 3 de agosto de $1872,150$.

«Los profesores alemanes», La Escuela Normal, n 106, 18 de enero de 1873, 11-17.

Lleras, Martín. «Método de lectura y escritura», La Escuela Normal, $\mathrm{n}^{\circ} 103,21$ de diciembre de 1872, 455-458.

. «Pedagojia. De la lectura en las clases superiores», La Escuela Normal, n 108, 25 de enero de 1873, 37-40.

. «Pedagogía, de los deberes particulares de los institutores y cómo deben cumplirlos», La Escuela Normal, n ${ }^{\circ}$ 101, 7 de diciembre de 1872, 450.

«Pensamientos sobre educación», La Escuela Normal, n 54, 13 de enero de 1872, 15.

Pérez Santiago, «Método típico», La Escuela Normal, n 108, 25 de enero de 1873, 28-30.

59 Acción Cultural Popular, Encuentro de delegados episcopales para la obra diocesana de escuelas radiofónicas, (Bogotá: Diócesis de Bogotá, 1968). 
"Presentación del tratato teórico i práctico de jimansia y calestenia», La Escuela Normal, nº 70, 4 de mayo de 1872, 398.

«Respuesta», La Escuela Normal, n 104, 18 de diciembre de 1872, 9-12.

\section{Bibliografía}

Acción Cultural Popular. Encuentro de delegados episcopales para la obra diocesana de escuelas radiofónicas. Bogotá: Diócesis de Bogotá, 1968.

Agulhon, Maurice. El círculo burgués; seguido de Una pequeña autobiografía intelectual. Editado por Pilar González Bernaldo. Buenos Aires: Siglo Veintiuno Editores, 2009.

Arias, Ricardo. El episcopado colombiano: intransigencia y laicidad 1850-2000. Bogotá: Centro de Estudios socioculturales, Ediciones Uniandes, Instituto Colombiano de Antropología e historia, 2003.

Barco, Eva. Lectura infantil para la enseñanza primaria. Bogotá: Imprenta de La Luz, 1897.

Bernal, Pablo Manuel. Introducción a Lectura infantil para la enseñanza primaria, de Eva Barco. Bogotá: imprenta La Luz, 1870 .

Botero Jaramillo, Natalia. «El problema de los excluidos. Las leyes contra la vagancia en Colombia durante las décadas de 1820 a 1840». Anuario Colombiano de Historia Social y de la Cultura $39, \mathrm{n}^{\circ} 2$ (2012): 41-68.

Burucua, José Emilio. "La mentalidad de las élites sobre la violencia en Colombia (1936-1949)”, Análisis político, núm. 29 (Sep-Dic. 1996): 99-101.

Cardoso Erlam, Néstor Roberto. Los textos escolares en Colombia: dispositivos ideológicos. 1870-1931. Ibagué: Universidad del Tolima; RUDECOLOMBIA, 2007. 
Chartier, Anne-Marie y Jean Hebrard. Discursos sobre la lectura (1880-1980). Traducido por Alberto Luis Bixio. Barcelona: Gedisa, 2005.

«Consejos para el pueblo». La Caridad. Lecturas de hogar, $\mathrm{n}^{\circ} 8$ (1864): 118.

Citolegia: nuevo método de lectura practica sin deletrear para uso de las escuelas primarias. Librería Colombiana Camacho Roldán y Tamayo, 1891.

Decreto Orgánico de Instrucción Pública (noviembre, 1870). Acceso el 1 de septiembre de 2015, http://www.pedagogica.edu.co/ storage/rce/articulos/5_8docu.pdf

Elías, Norbert. Deporte y ocio en el proceso de la civilización; traducción de Purificación Jiménez. México: Fondo de Cultura Económica, 1995.

Fairclough, Norman. Language and power. New York: Longman, 2001.

Littau, Karin. Teorías de la lectura: libros, cuerpos y bibliomanía. Traducido por Elena Marengo. Buenos Aires: Manantial, 2008.

Loaiza Cano, Gilberto. «El maestro de escuela o el ideal liberal de ciudadano en la reforma educativa de 1870», Historia Crítica, $\mathrm{n}^{\circ} 34,(2007): 62-91$.

López Sánchez, Olivia. «La higiene popular dirigida a las mujeresmadres: estrategias de la cruzada médico-higienista en la sociedad mexicana del porfiriato» En Al otro lado del cuerpo. Estudios biopolíticos en América Latina. Compilado por Hilderman Cardona y Zandra Pedraza. Medellín: Universidad de Medellín, Facultad de Ciencias Sociales y Humanas, 2014.

McGraw, Jason. «Purificar la nación». Revista de Estudios Sociales, $\mathrm{n}^{\circ} 27$ (2007): 62-75.

Ortiz, José Joaquín. «Prospecto», La Caridad. Lecturas del hogar, ${ }^{\circ}$ $1,(1864): 2-3$. 
Restrepo Mejía, Martín. Citolegia citográfica por la cual se enseña rapidamente a leer y a escribir. Libro primero de lectura. Tip. de Castellanos \& Ruiz, 1917.

Spencer, Herbert. «De la educación intelectual moral y física», $L a$ Niñez: semanario infantil Ilustrado, $\mathrm{n}^{\circ}$ 2, (1914), 17.

\section{Citar este artículo:}

GuzmánMéndez, Diana Paola. «La enseñanza dela lectura como profilaxis: el Decreto Orgánico de Instrucción Pública: entre la caridad y la instrucción». Historia Y MEMORIA, n 13 (2016): 121-149. DOI: http://dx.doi.org/10.19053/20275137.5202 